\title{
27. Synthesis and future research directions
}

\author{
Satu Teerikangas, Katariina Koistinen, Tiina Onkila and \\ Marileena Mäkelä
}

\section{INTRODUCTION}

The aim of this chapter is to provide a synthesis of the findings and knowledge gathered across the handbook's chapters. The main contribution of this handbook is to offer an integrative perspective on sustainability agency. In doing this, we begin to integrate the currently scattered research on sustainability agency. Each of the invited chapters reviewed a particular type or angle to sustainability agency, either within a discipline or literature, but often crossing disciplines. By pulling this knowledge together, this handbook provides a meta-level integration of the already integrated phenomenon - or literature-based reviews provided by the handbook chapters. The findings of the handbook bear significance not only per chapter, but also at the handbook level given the multiplicity of perspectives to sustainability agency offered. In this synthesis chapter, we seek to integrate the findings from across the handbook, thus offering an integrative perspective on sustainability agency, based on a meta-review of the handbook's chapters.

We proceed in this chapter as follows. We first provide a methods-based overview of the review approaches adopted by the handbook authors, along with the methods-related future research directions suggested by the handbook's authors. This leads us to a discussion on sustainability, agency, and sustainability agency, as viewed by the handbook's chapters, based on which we offer a definition and characteristics of sustainability agency. In the third section, we discuss research gaps and offer directions for future research. The final section concludes the handbook.

\section{A REVIEW-BASED HANDBOOK}

In this section, we analyze how the chapters were methodologically set up and how the author teams conducted their reviews. Our book was set to provide a broad overview at the intersection of agency and sustainability. In total, we received 25 chapters delving into agency and sustainability across disciplines. All the chapters of the book are presented in Table 27.1. In total, the reviews of this handbook cover over 1,400 publications.

The reviews of the chapters represent more than half a decade of research on sustainability agency, as the chapters' reviews range from 1965 to 2020. Zooming closer, in their reviews, authors especially placed emphasis to the years after the turn of the millennium. This may be explained by the fact that sustainability science has evolved at the turn of the millennium (Kates et al., 2001; Clark \& Dickson, 2003).

Taking a closer look, most author teams (13) employed a subjective literature review (e.g. Hoppe) in their chapters. In turn, seven author teams included a rigorous systematic review 


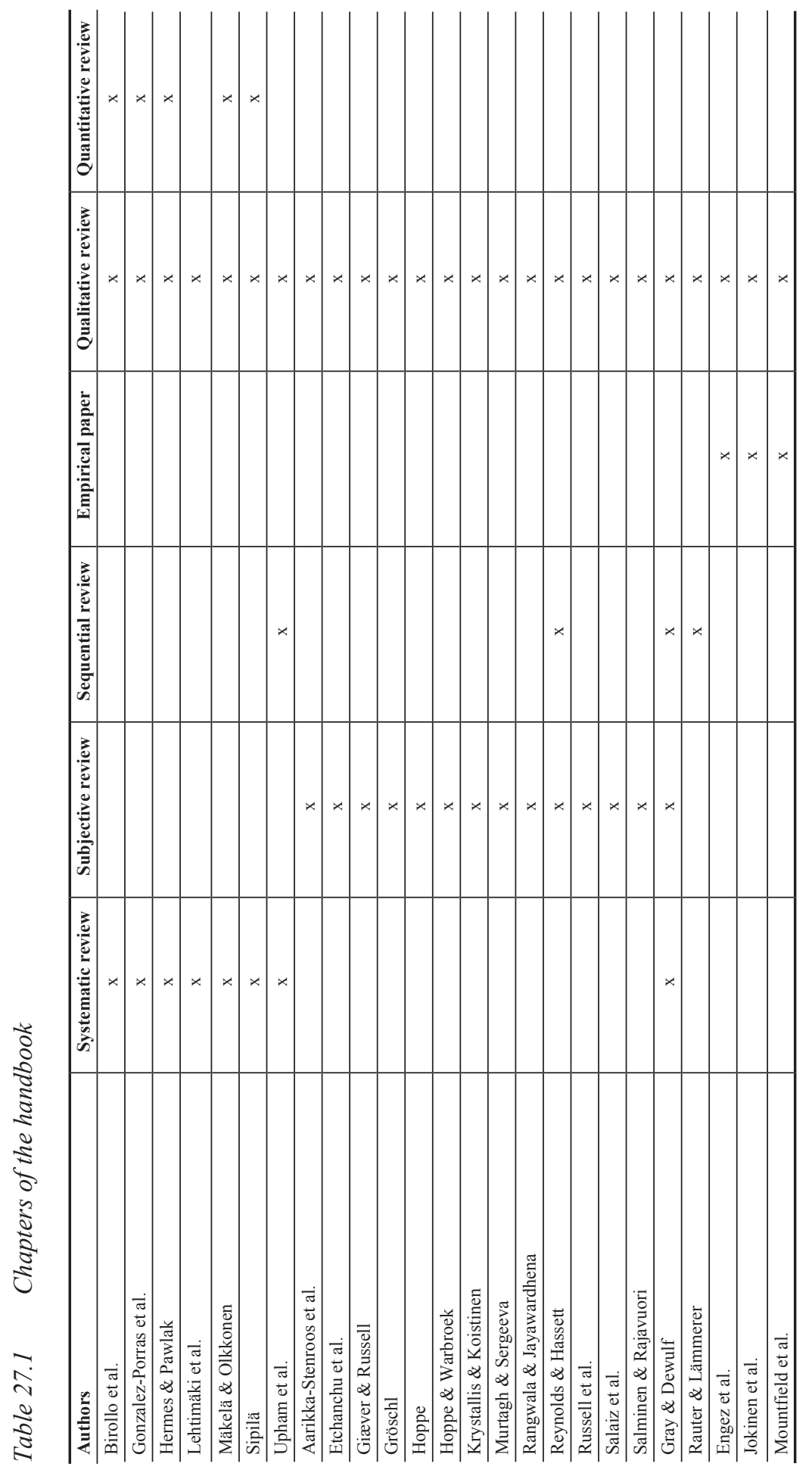


(e.g. Gonzalez-Porras et al.) in their chapters. Systematic literature reviews utilized Scopus, Google Scholar, Science Direct, Emerald Insight, ABI/Inform Global ${ }^{\circledR}$ and JSTOR Business Collection Databases. Systematic literature reviews are portrayed in more detail in Table 27.2. In the book, two author teams (Gray \& Dewulf; Rauter \& Lämmerer) extended their previously published reviews. All the authors described their sample and findings qualitatively. In addition, five author teams included a quantitative review (e.g. Birollo et al.) in their chapters. Three author teams included an empirical section, be it as regards distributed agency in an urban living laboratory (Engez et al.), the relationship between material and human agency in the context of circular economy (Jokinen et al.), or the role of middle managers in implementing sustainability strategy (Mountfield et al.).

While authors brought forward numerous methods-related suggestions for future research, below we highlight those themes that cut across several of the handbook's chapters. To begin with, most of the chapters called for more qualitative research methods to be used in the study of various forms of sustainability agency. In particular longitudinal research methods are called for, in the form of e.g. observational studies and diary studies. All the while, multi-level studies are needed, accounting for the multitude of actors shaping sustainability transitions. Moving on, research ought to cover the global span of sustainability agency, thus an appreciation of the variety of local contexts within which agency shapes sustainability transitions is needed. Going forward, academics need to carefully consider their agency vis-à-vis sustainability transitions. How do academics exercise their sustainability agency? From science communication, there are calls for scholars toward engaged forms of scholarship, action research and community-engagement. In some contexts, there might be a need to educate actors, as in the context of developing countries.

\section{MAKING SENSE OF SUSTAINABILITY AGENCY}

We invited authors to write to the handbook as regards the perspective of sustainability agency that they have expertise in. Beyond this, as editors we gave little steer as to the way in which authors ought to define the terms sustainability, agency or sustainability agency. In the next sections, we proceed to an overview of how these terms, i.e. sustainability, agency, and sustainability agency have been captured by the handbook's author teams, and the type of theorizing used in this endeavor. The section ends with a synthesis of what sustainability agency, based on the handbook's inputs, can be considered to be, as well as an appreciation of its paradoxical nature.

\section{Sustainability}

The way in which sustainability was approached per chapter differed, see Table 27.3. The broad context of sustainability (Jokinen et al.; Mäkelä \& Olkkonen), sustainable development (Birollo et al.), as well as the Anthropocene and wicked problems (Gray \& Dewulf) were used by some authors to set their chapter within the sustainability setting. Several chapters were set into the context of sustainability transitions (Upham et al., Krystallis \& Koistinen; Hoppe; Engez et al.), at times coupled with systemic change (Gonzalez-Porras et al.). It deserves mention that sustainability in the handbook is mostly studied via environmental sustainabil- 


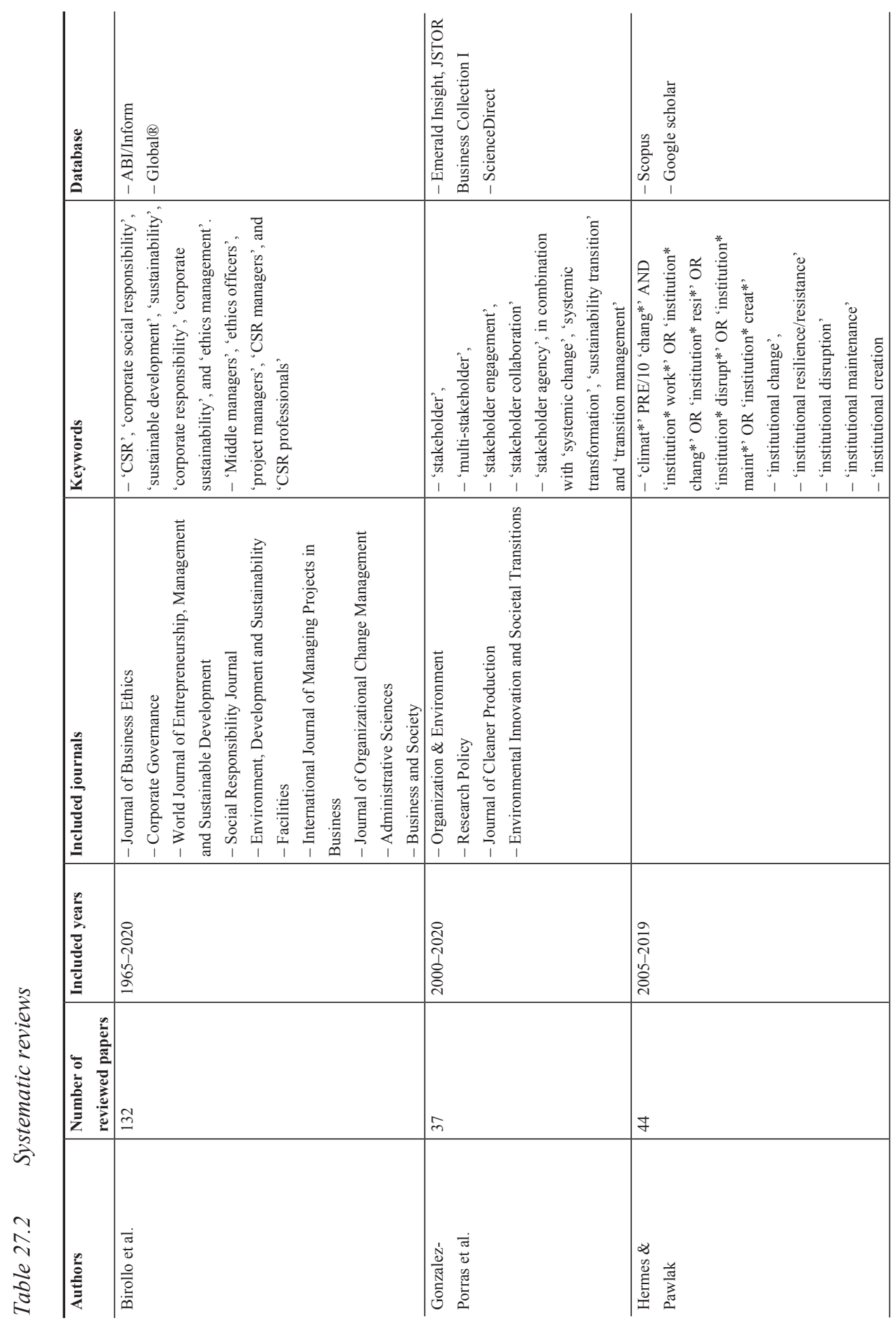




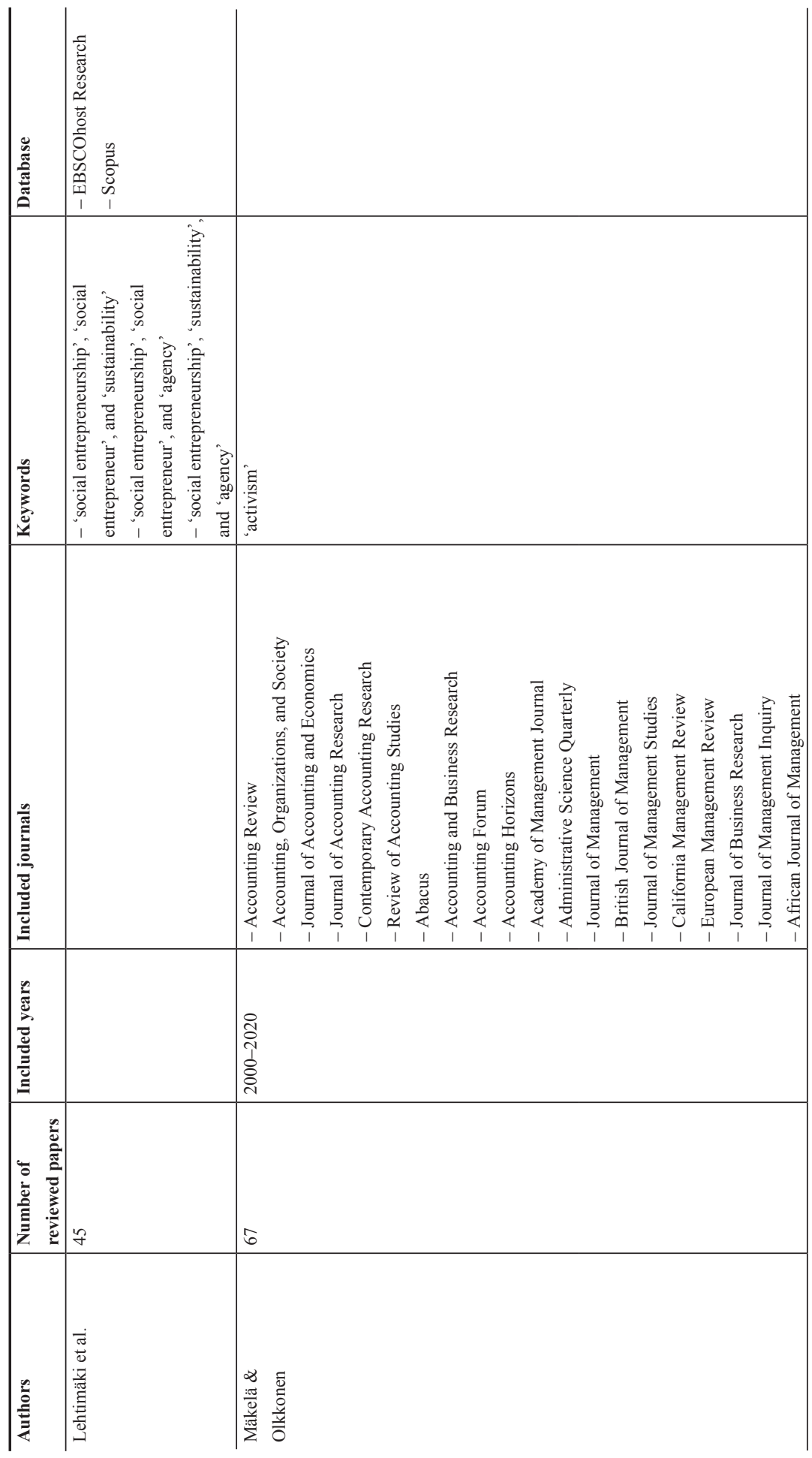




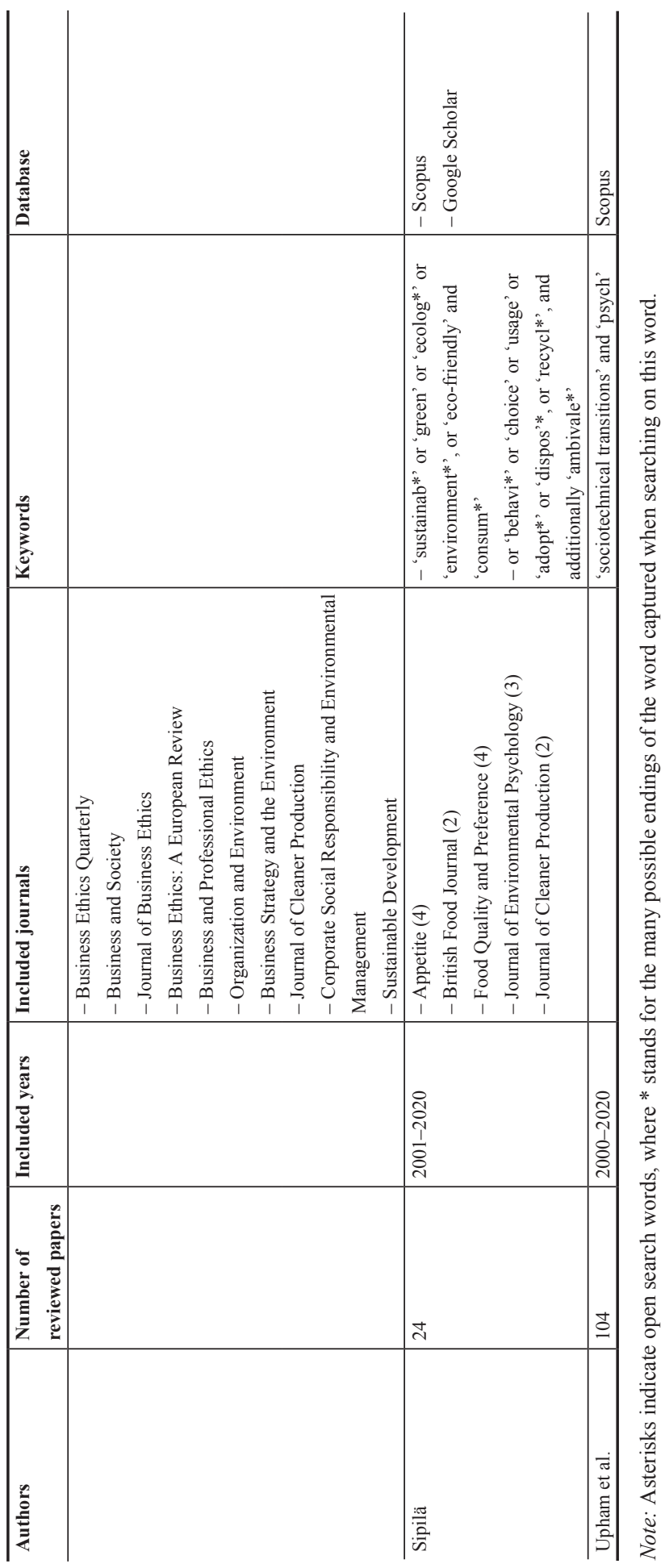


ity, with the exception of one chapter focused on social sustainability in the Indian context (Rangwala \& Jayawardhena).

Some chapters focused on one major sustainability challenge. To begin with, some chapters focus on climate change, whether discussed from the perspectives of institutional entrepreneurship (Hermes \& Pawlak), social movements (Etchanchu et al.), or the role of local governments (Hoppe). All the while, other chapters focused on the circular economy addressed via the role of ecosystems (Aarikka-Stenroos et al.) or the relationship between human and material agency (Jokinen et al.). The contexts of sustainable energy transitions and the role of citizen collectives therein are the focus of Hoppe and Warbroek, while new sustainable urban area development is studied by Engez et al.

Many built on the contexts of sustainability in corporate contexts whether labeling it as corporate sustainability, CSR, or organizational sustainability be it to study top managers (Salaiz et al.), middle managers (Birollo et al.), employees (Russell et al.), corporate strategy (Rauter \& Lämmerer) or mergers and acquisitions (M\&A) (Reynolds \& Hassett). Two chapters focused in particular on sustainable consumption (Sipilä; Rangwala \& Jayawardhena). Some chapters were sustainability-wise set onto the actor type studied, as in the chapters on social entrepreneurship (Lehtimäki et al.), or sustainability work (Giæver \& Russell), while others set sustainability onto the discipline they studied it from, as in the example of the chapter on law and agency (Salminen \& Rajavuori), or construction and project management (Murtagh \& Sergeeva). In addition, various contexts of study are used, be it developing countries and the example of India to discuss sustainable consumption (Rangwala \& Jayawardhena), informal economies (Gröschl), or specific industries such as the food industry as an example to illustrate corporate sustainability strategy (Rauter \& Lämmerer), or the goods and retail sector to illustrate the barriers to implementing sustainability strategy (Mountfield et al.).

\section{Agency and Sustainability Agency}

Based on the handbook's chapters, we confirm the handbook's initial assumption that sustainability agency has not been previously used as a term. We observe that the handbook chapters offer a proliferation of terms and theorizing related to the phenomenon of sustainability agency. In this section, we proceed to an overview of how the concepts of sustainability agency and agency are approached by the handbook's authors. The reader is encouraged to refer to Table 27.3.

To begin with, the handbook offers a myriad of operationalizations of the concept of sustainability agency. To this end, each chapter introduces an actor or phenomenon type that is considered representative of sustainability agency. For one, via the lens of an individual-level role in the organizational hierarchy such as strategic leaders (i.e. top managers, CEOs, board of directors), middle managers, employees, individual consumers, citizens or individual actors in a broad sense. For another, via the lens of an active sustainability agent different proxy terms for sustainability agency are proposed, be it at the level of an individual such as a sustainability worker, an ecopreneur, a social entrepreneur, a sustainability activist, or an institutional worker, or at the collective level as in the examples of social movements, grassroots movements, citizen collectives, and community energy cooperatives. Third, at the organized collective level as regards organizations as in the examples of national and local governments, companies, within and across organizations as in the example of projects or distributed agency, at the level of industries, as in the examples of construction, energy, or 


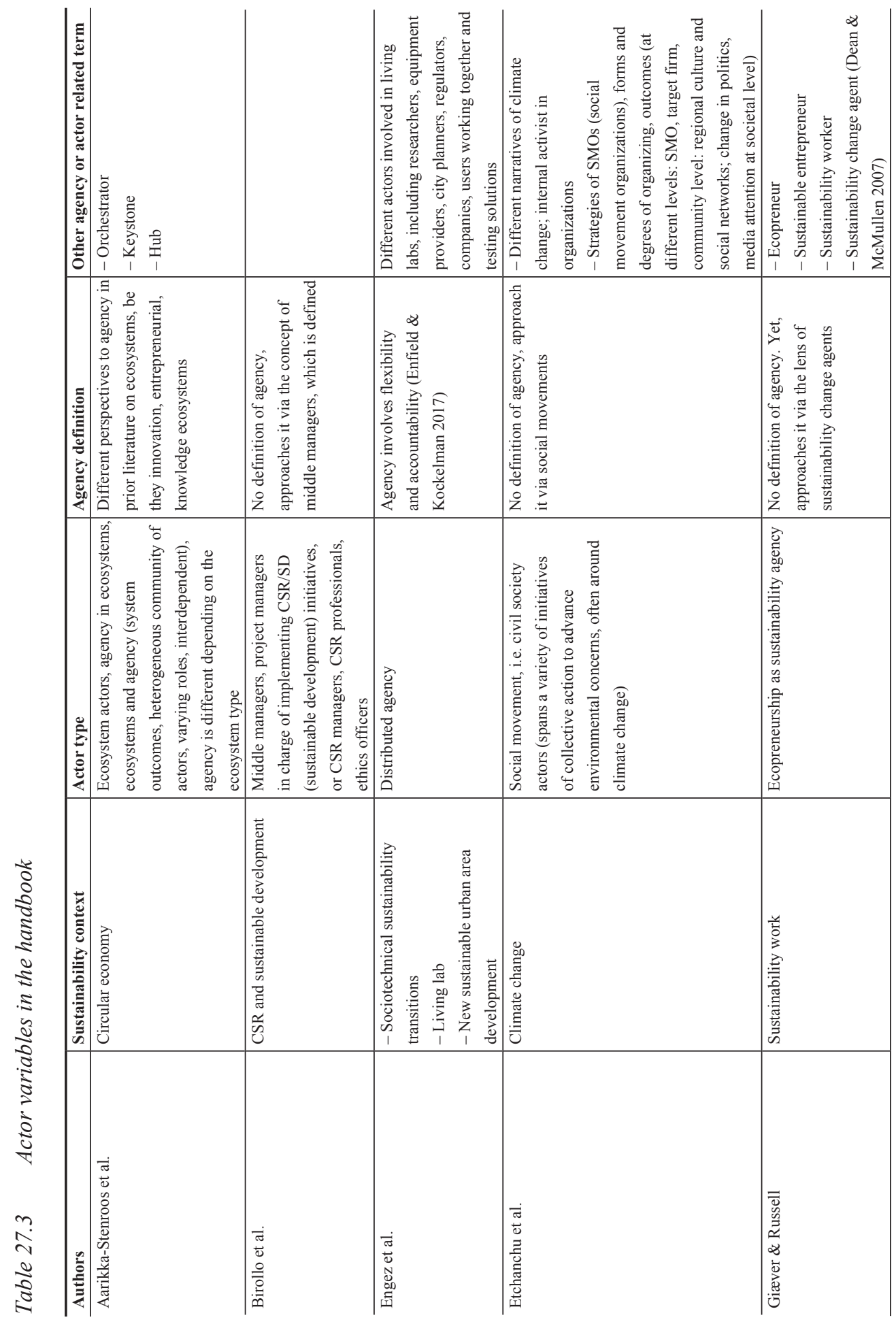




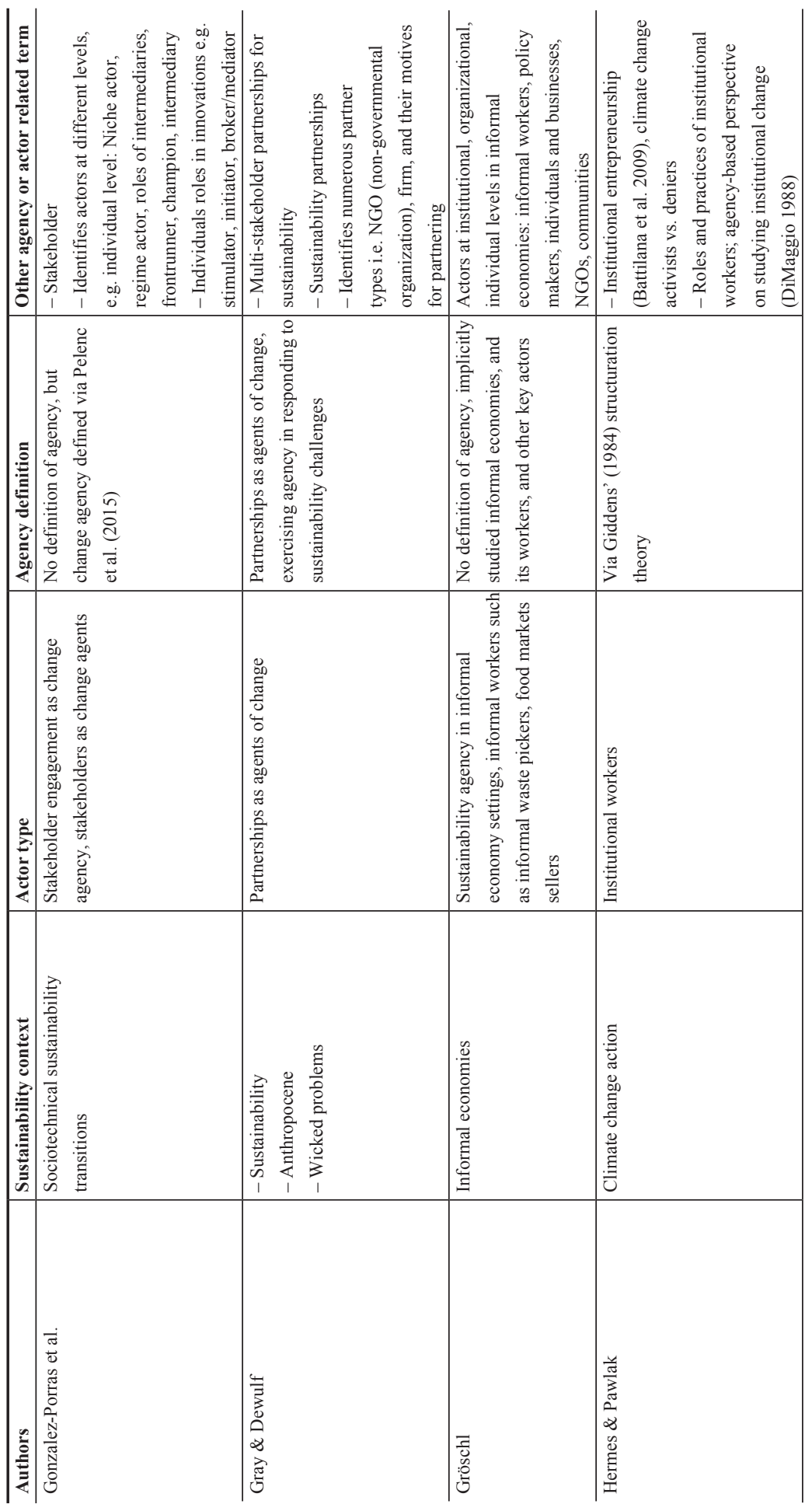




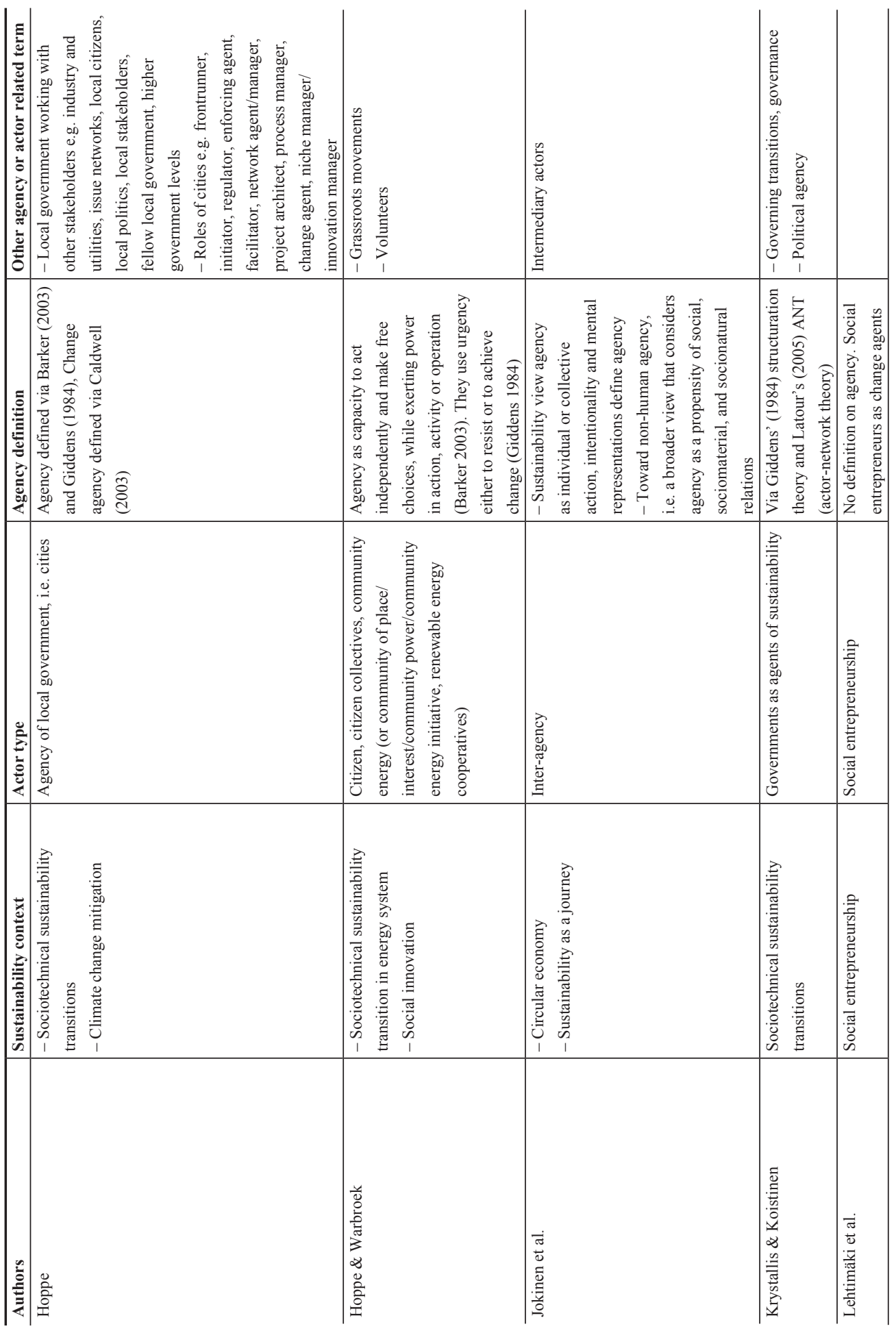




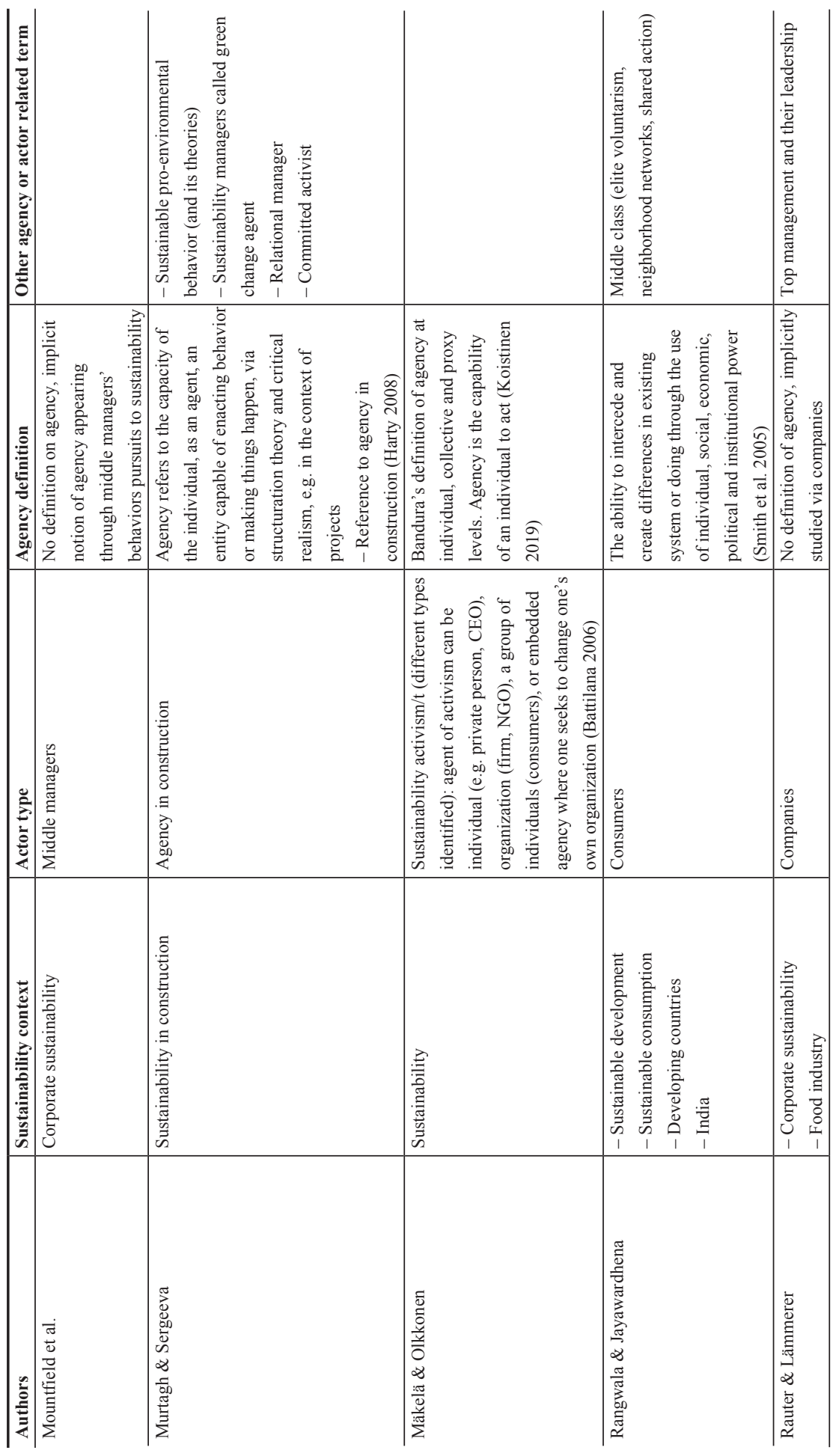




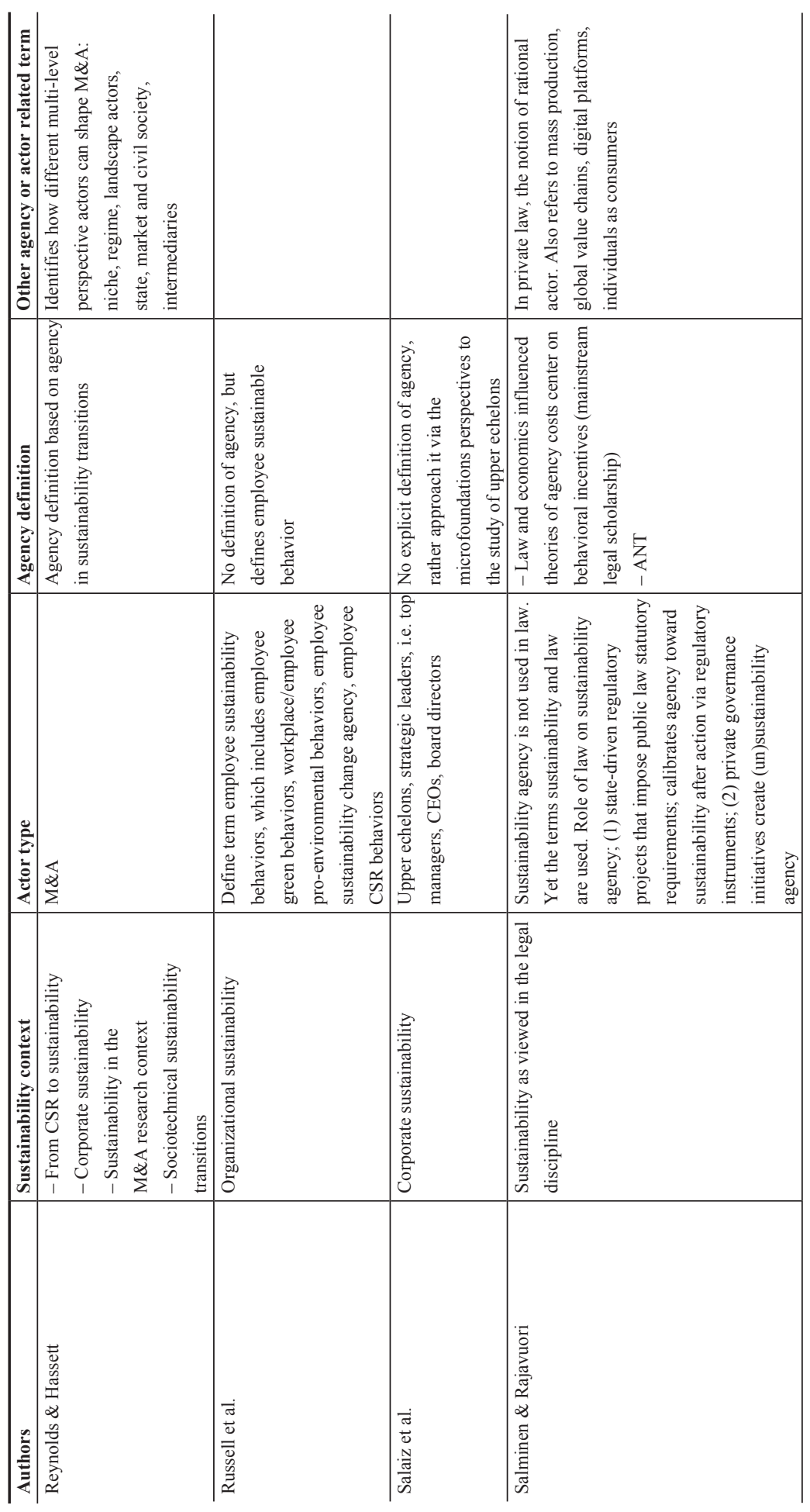




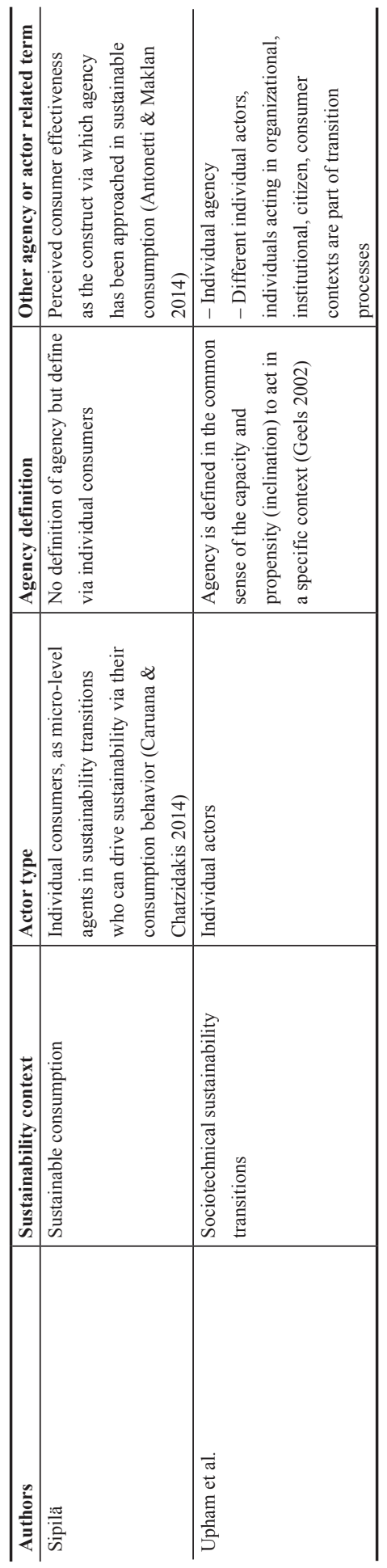


food industries, or at the abstract, institutional level referring to legislation as well as formal and informal economies. Fourth, agency is operationalized within a set phenomenon, be it as regards multi-stakeholder partnerships, M\&A, networks, ecosystems, living laboratories, or via a proxy term such as stakeholder engagement. Finally, agency is operationalized with respect to material and the relationship between humans and material. In so doing, the handbook's chapters refer to distinct types of actors or types of agency.

Yet, taking a closer look, the handbook's chapters approached the concept of agency theoretically in numerous ways. Some authors explicitly defined their view of agency. In this regard, existing definitions were used, referring to the works of Giddens (1984), Bandura (2006), Barker (2003), or Enfield and Kockelman (2017) on agency. Others based their view of agency on existing literatures including sustainability transitions or the multidisciplinary field of ecosystems research, wherein in each the notion of agency is actually discussed in many different ways. Still others provided reviews of agency via psychological, sociological, management or legal theory. Taking a closer look, theoretical underpinnings on agency often stemmed from sociology (e.g. Etchanchu et al.) and psychology (e.g. Sipilä; Murtagh $\&$ Sergeeva). Sociological underpinnings were addressed, for example, via the sociology of expectations and the notion of ambivalence. In turn, psychological underpinnings took forms, such as, cognitive dissonance theory and theory of planned behavior. As regards management, theoretical underpinnings related to stakeholder theory (e.g. Gonzalez-Porras et al.), institutional theory (e.g. Hermes \& Pawlak), or microfoundations theory (e.g. Salaiz et al.). The perspectives of law and economics as regards agency were also reviewed (e.g. Salminen \& Rajavuori). Thus, agency-based theorizing in the chapters cut across the social sciences.

What is more, we observe a proliferation of 'agency' related concepts across the handbook. These represent instances where the term agency is used to introduce a concept representative of sustainability agency. This is the case with the concepts of individual agency, middle managers' agency, employee agency, purposeful agency, consumer agency, actor agency (e.g. in ecosystems), distributed or decentralized agency, shared agency, material agency, inter-agency, academic agency, economic agency, moral agency, and political agency.

It deserves recognition that instead of the term 'agency', many chapters adopt the term 'change agency' or 'change agent'. On the one hand, some chapters make this explicitly by referring to prior theory or literature in their definitions. It is thus that the concepts of sustainability change agent (Dean \& McMullen, 2007) and change agency (Barker, 2003; Caldwell, 2003; Pelenc et al., 2015) are referred to. Subsequently, chapters in Part II titled 'active agency' adopt a change agent perspective to the agency-type they are reviewing. This is visible in the chapters on ecopreneurs, social entrepreneurs, activists, institutional workers, social movements, and citizen collectives. Some chapters use the agency metaphor to introduce a change agent perspective to an existing actor- or phenomenon-based literature. As regards actors, this is the case as regards the proposed view of employees or local government (e.g. cities) as sustainability change agents. As regards phenomenon-based literatures, this is the case as regards multi-stakeholder partnerships, M\&A, stakeholder engagement, all proposed as sustainability change agents. Finally, some authors' view of change agency is to be read between the lines, as in the examples of the role of governments, the introduced notion of inter-agency, and sustainable consumption. 


\section{Multidisciplinary Theoretical Grounding}

In order to address the notion of sustainability agency, the chapters coupled their theoretical base into at least two, sometimes more, disciplines, theories and/or literatures (see Table 27.4). To begin with, one of the theoretical and disciplinary lenses in the handbook chapters relates to sustainability. It is thus that chapters are theoretically positioned into the literatures related to sustainability transitions in general (Upham et al.; Krystallis \& Koistinen; Hoppe; Rauter \& Lämmerer; Gonzalez-Porras et al.; Reynolds \& Hassett; Engez et al.), focus on sustainable energy transitions (Hoppe \& Warbroek), or sustainability governance (Salminen \& Rajavuori). Some of the authors draw from the disciplines of environmental psychology (Sipilä), environmental sociology (Etchanchu et al.), environmental policy (Jokinen et al.), or theories such as environmental theory (Hermes \& Pawlak). Many chapters are focused on the realm of CSR in general (Salaiz et al.; Birollo et al.; Russell et al.; Giæver \& Russell; Rauter \& Lämmerer; Reynolds \& Hassett), sustainable consumption (Sipilä; Rangwala \& Jayawardhena), or stakeholder theory (Gonzalez-Porras et al.) in particular.

All the while, in order to approach agency from a particular angle, chapters are simultaneously positioned (at least) onto another disciplinary context. For this purpose, chapters draw from a wide range of disciplines ranging from economics (Gröschl), psychology (employees, ecopreneurs, Murtagh \& Sergeeva), social psychology (Upham et al.), public policy (Gray \& Dewulf), urban governance (Hoppe), or science and technology studies (Jokinen et al.). A number of the chapters focus on organizational actors, hence the role of business studies is visible throughout the handbook, be it as regards accounting (Mäkelä \& Olkkonen), marketing (Sipilä), or management studies (employees, ecopreneurs; Mäkelä \& Olkkonen; Etchanchu et al.; Gröschl; Gray \& Dewulf), with some authors focusing on sub-disciplines of management such as strategic management (Birollo et al.; Krystallis \& Koistinen; Rauter \& Lämmerer), organization studies (Lehtimäki et al.; Hermes \& Pawlak; Etchanchu et al.; Reynolds \& Hassett), or construction and project management (Murtagh \& Sergeeva). Within these fields of research, authors review the phenomenon-based literature(s), across sub-disciplines, on certain types of agency such as ecosystems (Aarikka-Stenroos et al.), partnerships (Gray \& Dewulf), or M\&A (Reynolds \& Hassett).

While authors combine theories and concepts related to sustainability with ones from another domain, they adopt different approaches. One approach is to assess how particular theories, such as psychological theories, have been used in sustainability transitions research (Upham et al.). Most chapters assess the studied sustainability agency at the crossroads of two disciplines (Birollo et al.) or across several disciplines (Hoppe; Mäkelä \& Olkkonen; Murtagh \& Sergeeva). Alternatively, authors have compared different theories to extend the prevailing appreciation of a particular kind of sustainability agency, as in the example of governmental agency (Krystallis \& Koistinen).

In closing, we point out that knowledge on sustainability agency is scattered across disciplines, phenomena, and actor types. While these bodies might at times talk to one another, in practice they have largely remained disparate. While their recurring theme relates to sustainability, it is thus that the contexts of sustainability transitions, corporate sustainability, or CSR tend to be literatures what most literatures refer to, yet the type of agency that is studied depends on the literature and discipline. It is thus that there can be significant overlaps between the work, while also areas of academic neglect. 


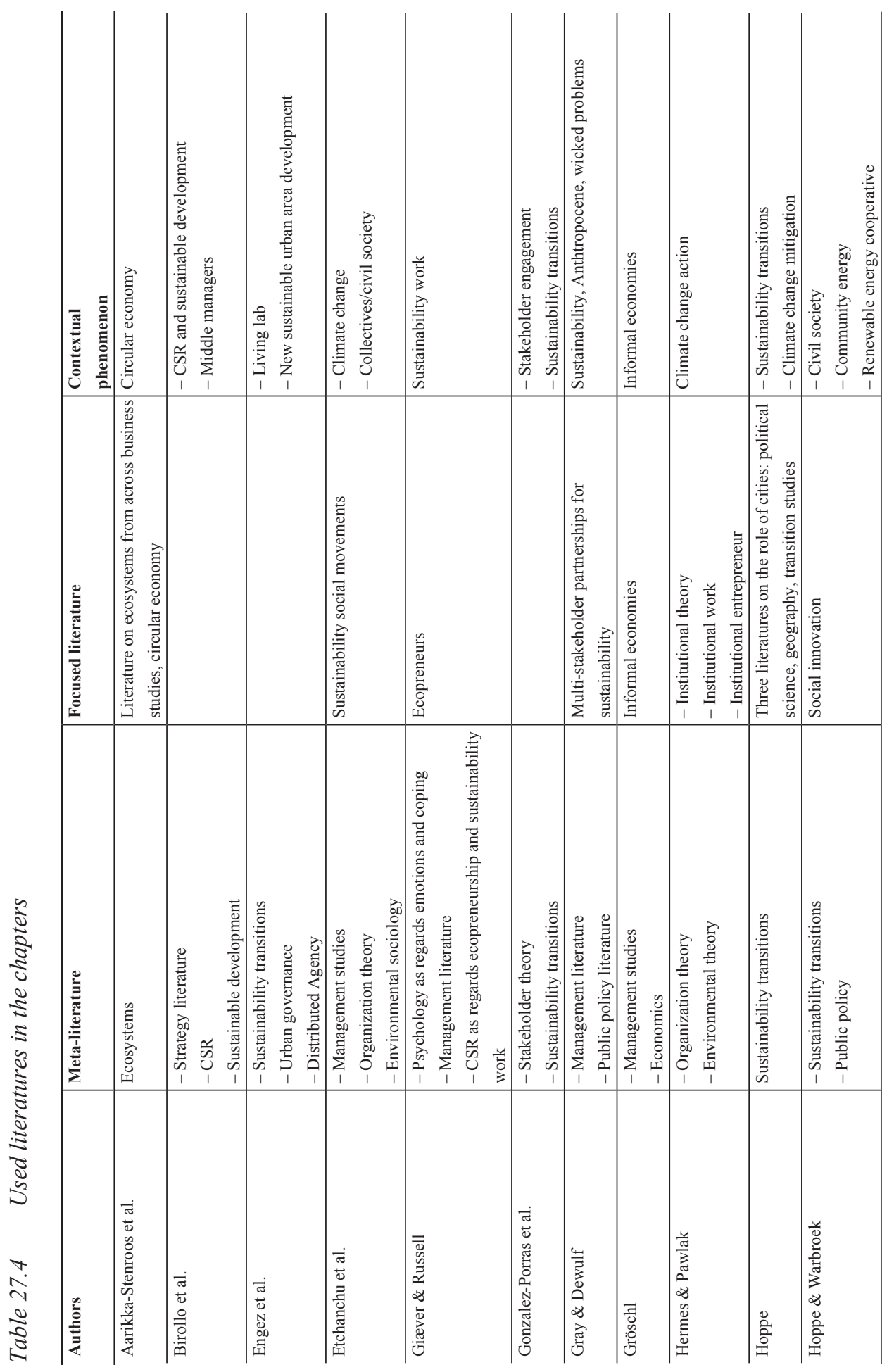




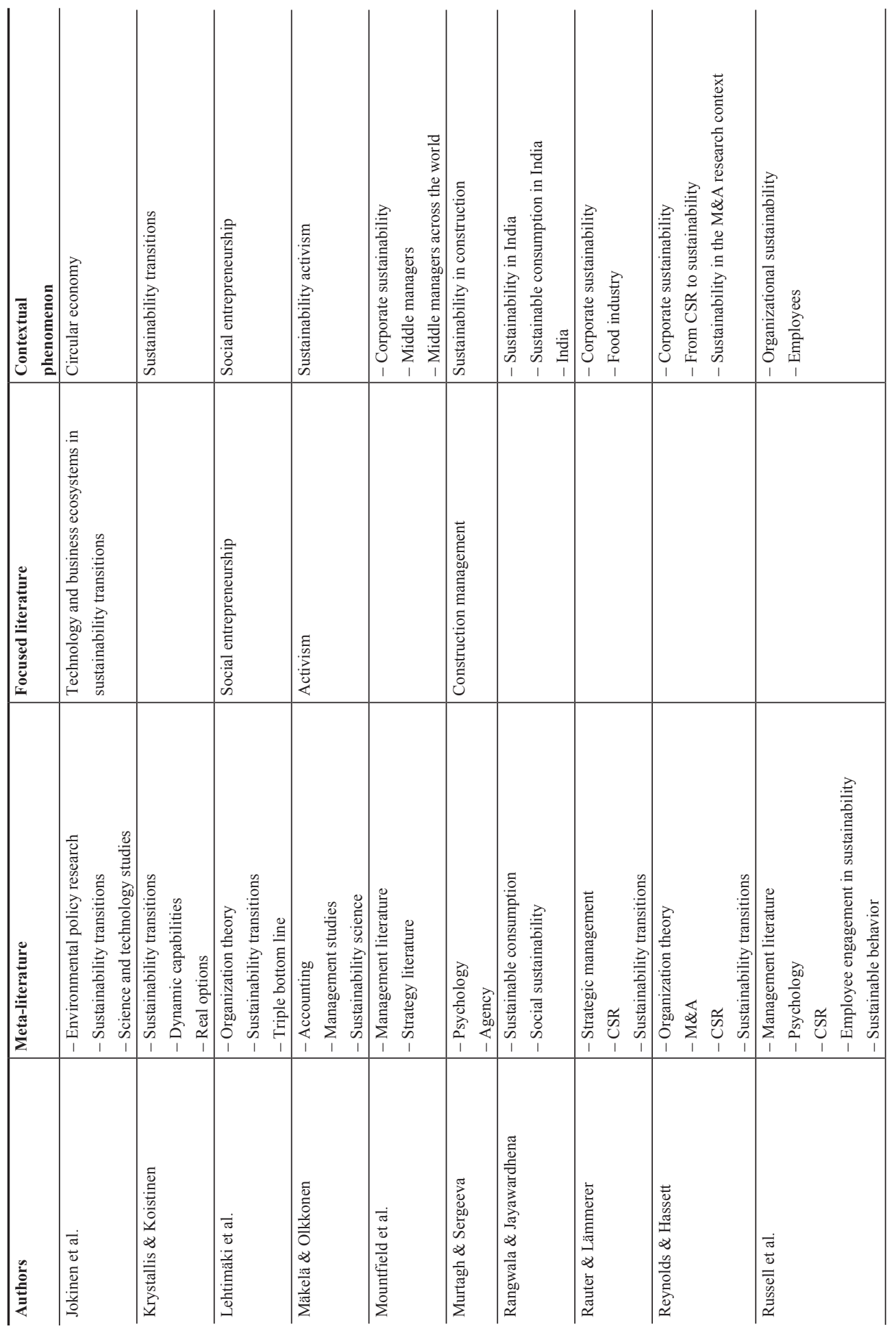




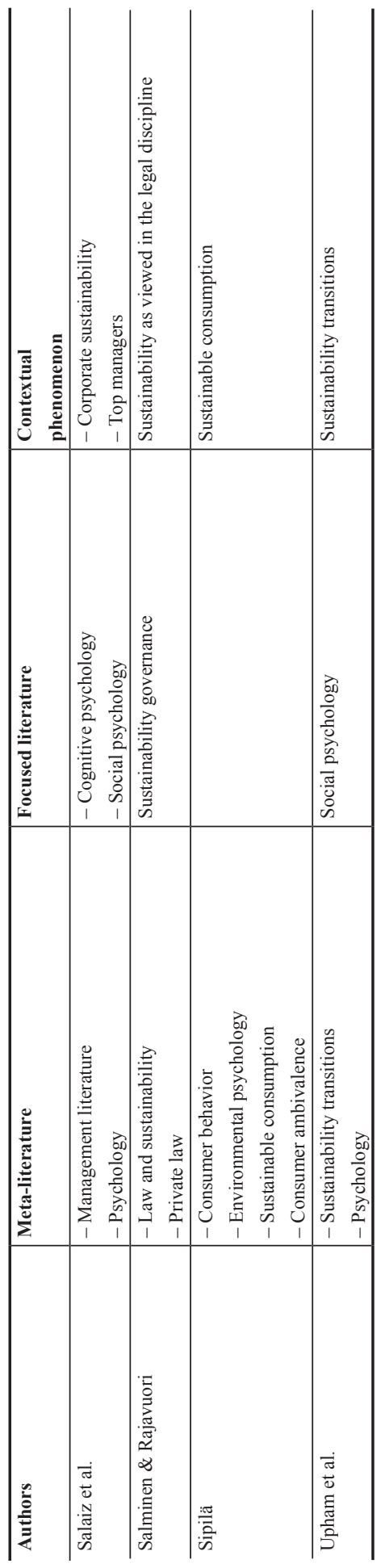




\section{Characteristics and Definition of Sustainability Agency}

In light of the multiplicity of terms and theories in use in the handbook, this section synthesizes the views provided across the handbook chapters as regards the nature of sustainability agency, answering the question: What is sustainability agency?

A first distinction needs to be made between human and non-human sustainability agency. This distinction matters in particular in the sustainability context. As regards non-human agency, it is thus that the agency of materials or nature deserves attention, in particular in contexts where materiality is present, such as the circular economy, use of natural resources, or the built environment (see Jokinen et al.). Yet, most of the handbook chapters adopt a perspective on sustainability agency as human agency, i.e. individuals' or collectives' intentional, proactive sustainability action that bears a relational component in that it often occurs in collaboration with others.

Upon a closer look, sustainability agency appears to be a phenomenon that is difficult to bind to any one level of analysis. At the individual level, the handbook brings forth the role of individual actors, which can refer to any individual acting in organizational, institutional, or community contexts as a professional, citizen, and/or consumer. The roles undertaken in formal organizational hierarchies, whether in business or public-sector organizations, can relate to strategic leaders (i.e. board of directors, top management teams, CEO), middle managers, as well as employees. When sustainability is part and parcel of one's professional role, the term sustainability worker is used. The roles of CSR manager, CSR professional, ethics officer, and project manager in charge of implementing CSR/SD initiatives are acknowledged. Individuals actively pursuing sustainability agendas include various types of activists, institutional workers and institutional entrepreneurs, as well as ecopreneurs and sustainability entrepreneurs.

The handbook identifies numerous examples of collective-level sustainability agency. Economies, be they formal or informal, as well as legislation, can be considered as bearing institutional-level sustainability agency. Sustainability agency can also reside in organizations, as in the examples of public and private organizations such as governments, cities and firms. Some organizations are more active sustainability agents than others. It is thus the handbook brings forth the role of activist organizations be they citizen collectives, grassroots movements, energy cooperatives, or social movements. Temporal forms of organizing, as via projects, are examples of temporally embedded sustainability agency that bring together individuals within and across organizations. Distributed agency provides an example of decentralized sustainability agency.

In addition to sustainability agency relating to various types of organizational and individual actors, it deserves mention that, within each identified actor category, there is further complexity, i.e. a further sub-categorization of actors. It is thus, for example, that a variety of types of activists, eco- and social entrepreneurs, citizen collectives, partnerships, ecosystems, and informal economy workers are identified in the respective chapters.

The notion of collaboration appears central to tackling Grand Challenges, which by their nature are so demanding that they cannot be solved alone by any one individual entity. In such collaborative instances, agency bears a relational element, i.e. individuals, organizations and/or material interacting with one another, performing their agency in interaction. For one, collaboration occurs between individuals and organizations. Such forms of sustainability agency are illustrated via the examples of stakeholder collaboration and engagement, 
multi-stakeholder and cross-sector partnerships, M\&A, and ecosystems. It deserves mention that, in many sectors, such as construction and the built environment, or the case of supply chain management, collaboration is part and parcel of the nature of the work conducted. Collaboration amid sustainability transitions can occur in particular places, such as living laboratories that provide local spaces for cross-sector exploration and innovation. For another, collaboration can occur between humans and materials. Such instances are termed inter-agency, reflecting the relational and emerging nature of this interaction (see Jokinen et al.). Third, collaboration occurs across levels of analysis. This is illustrated in the examples of stakeholder engagement, partnerships, cities, informal economy, sustainable consumption, legislation, and the construction industry. Thus, much of the work of sustainability agents occurs in the interaction, negotiation, and collaborating with a broad spectrum of stakeholders. The significance of collaboration is raised in numerous chapters. Thus, a collaborative mindset appears to be a central tenet of sustainability agency.

The question of local vs. global is an inherent tension across the handbook. On the one hand, sustainability agency can occur in specific places. Across the handbook, authors provide examples of such places as in the specific context of living laboratories, or local communities, cities, and countries. On the other hand, the chapters bring forth a view of sustainability agency, regardless of actor or phenomenon type, as being involved in action that spans local, regional, national, and potentially global domains. In other words, while sustainability agency can occur in a particular location, or place, when enacted, it connects with broader spheres of influence cutting across levels of analysis from local to global.

All the while, the very notion of who is a sustainability agent appears to be shifting. Research has traditionally attributed agency to active actors, such as activists, institutional workers, ecopreneurs, activist organizations such as social movements, actors in leading roles, such as top managers, or sustainability professionals, such as CSR managers. Yet it appears that new forms of sustainability agency are emerging, be it as regards middle managerial agency, employee agency, novel forms of activism, stakeholder engagement as agency, partnerships as agency, or private law as agency. It is thus that via the handbook a view of sustainability agency as a broadening space of proactive behavior toward sustainable futures emerges.

Given that sustainability agency occurs at different levels of analysis, can be human and non-human, and involves collaboration, it is understandable that the theoretical bases for appreciating sustainability agency are diverse. While in the study of individual actors psychological theories are used, in the study of activists shaping the prevailing agenda oftentimes sociological theories are referred to. All the while, classics in law and economic theory are based on a transactional view of agency, while the study of material agency is based on sociomateriality and science and technology studies. Such diversity in the perceptions of agency is mirrored with basic theorizing on agency, which as noted in the introductory section of this chapter, is equally diverse and multidisciplinary.

In synthesis, it is via an overview of the operationalizations in use in this handbook that an appreciation of sustainability agency emerges. A reading of the handbook chapters leads us to define sustainability agency as intentional, proactive individual- or collective-level action geared toward sustainable futures, also involving interaction with non-material forms of agency. Further, change agency is increasingly viewed as part of a sustainability agent's modus operandi. Moreover, an increasingly diverse set of actors is considered as sustainability agents, thus the remit of sustainability agency is on the increase. 


\section{The Paradoxical Nature of Sustainability Agency}

Many of the chapters bring forth the paradoxical nature of sustainability-related agency, be it in professional, activist, consumption, partnership, or institutional contexts.

In the context of firms, as regards top management, there is a dilemma between responsible vs. irresponsible decision-making, and as regards middle managers, the (potential) clash between personal vs. organizational values is raised. In the context of local government, i.e. cities, the question of lack of capacity is raised, whereas in the case of citizen collectives, the lack of professionalism is an issue. Those actively pursuing sustainability agendas, such as sustainability workers, face emotional tensions between meaningful careers and the resistance faced in execution. The different narratives around climate change, for example, differentiate between protagonists and antagonists. Consumers, on their side, face ambivalence over consumption choices. Notwithstanding, the question of coping and resilience is brought forward as a means for individuals, in their professional, activist, or consumer roles to deal with the tensions and paradoxes involved in sustainability work.

Paradoxes are also inherent in collaborative forms of sustainability agency. In the context of multi-stakeholder partnerships, tensions as regards views of what is sustainability as well as trade-offs related to power imbalances are not unusual. Intriguingly, to date the bulk of M\&A research has remained agnostic to questions of sustainability. Amid such a state of affairs, the field of sustainability strategy continues to perceive firms growing solely via organic growth. Such a perspective actively disregards the continuous M\&A activity that oftentimes is not driven by sustainability agendas. In other words, a root cause of the unsustainable state of the world, i.e. firm growth, remains under-scrutinized.

Furthermore, also sustainability agency in the form of governance can be mired by paradoxes. The field of law brings forth a mixed message given that, formally, regulation intervenes via state-driven law, yet in the context of private law regulating global business, there is little in the form of legal frameworks to secure the sustainability agency of private transactions, be it as regards property, business transactions, multinationals, supply chains, or digital platforms. While top-down governance via legislation and policy interventions as well as economic support are considered an important means of transitioning countries toward lower-carbon economies, such instruments are amiss in the context of informal economies. Yet a closer look at these contexts shows examples of bottom-up sustainability agency. Indeed, actors can be proactive sustainability agents, as in the example of waste pickers in developing countries. This blurs the question of who is an active sustainability agent and who is not, and the role of top-down governance therein.

\section{FROM RESEARCH GAPS TOWARD FUTURE RESEARCH DIRECTIONS}

Based on a reading of the handbook chapters, their comparative analysis, and meta-synthesis, a number of research gaps can be identified, leading to numerous future research directions. We start this section with an overview, followed by focused looks at future research on individual-level agency, active agency, and collaborative forms of agency.

Going forward, a shift in meta-narratives, discourses, as well as economic and legal paradigms is called for. There is need for future-oriented narratives that bring hope and energy 
instead of fear and distress (Etchanchu et al.). In light of the dire state of the planet's ecological system, new economic paradigms are called for that account for the value of the natural environment, instead of having (oftentimes unsustainable) economic growth as the sole objective of society and business. Hybrid economic models accounting for formal and informal economies are needed (Gröschl). In business, the prevailing economic and accounting perspective of actors, focused on costs and financial efficiency, appears to provide a one-sided perspective to human agency (Murtagh \& Sergeeva).

In a broad perspective, the focus in the study of sustainability agency has been on developed vs. developing countries (Rangwala \& Jayawardhena), on formal vs informal economies (Gröschl), and the role of national legislation vs. private law governing business transactions within and across national and digital boundaries (Salminen \& Rajavuori). Such a view bears severe limitations. For one, the bulk of the world's population lives in developing countries, and a majority of these work in informal economies. Taking a critical stance, this means that research on sustainability agency is lacking a truly global perspective, ignoring the dynamics of informal economies and concerns of workers therein as well as the sustainability agency concerns in developing countries. For another, while legislation is oftentimes considered an important instrument of sustainability governance, a critical look at this body of literature and practice shows its limitations vis-à-vis the study and practice of private law. These omissions bear implications on the (un)sustainability of business practices, as legal frameworks to govern private business are based on the principle of business autonomy. Taking a critical stance, the review of Salminen and Rajavuori provides cruel proof of the underlying mechanisms of unsustainable business practice, in so doing calling for a renewal of private law instruments.

In both the literatures of sustainability science as well as firms' sustainability strategies, the focus traditionally has been on macro-level phenomena at the expense of the micro-level. In CSR, attention is now shifting from a study of institutions and organizations to the study of actors. In sustainability science, the focus is shifting from the study of governance and collectives as actors toward individuals as actors (Upham et al.). In construction management research, research has focused on technology and policy instead of actors. Across disciplines, there has been interest in how organizations affect employees' behaviors, instead of turning the question upside down, and looking at how individuals, be they middle managers or employees, actively drive sustainability change within their employing organizations (Russell et al.). Notwithstanding, calls for microfoundations perspectives to the study of individual actors, be it inside organizations, such as top managers (Salaiz et al.), or within the broader economy, have been made (Gröschl).

Such a state of affairs has been paralleled with a shift of interest from a top-down perspective to change in societies and organizations, toward a bottom-up perspective, and increasingly a perspective combining both bottom-up and top-down engagement. In this respect it deserves mention that in countries where top-down societal sustainability governance appears lacking, as in the case of India, this is, in part, at times, compensated by bottom-up action, for example by informal waste pickers or middle-class citizens driving sustainability (Rangwala \& Jayawardhena).

Taking a closer look at businesses' sustainability strategies, in their review Rauter and Lämmerer critically observe prior research to have shown keen interest toward the question of 'why' firms pursue sustainability strategies. Such an interest has overshadowed interest in the question of 'how' sustainability strategies are implemented in business organizations and 'who' is involved in this endeavor. In a broader perspective, such a positioning mirrors 
strategic management research, where a planning focus has traditionally eclipsed interest in implementation. Moreover, research has tended to identify CSR strategy as a separate strategic activity within the broader remit of a firm's business strategy. Hence calls for all-organization encompassing sustainability strategies have been made. Strikingly, there appears a paucity of appreciation of the role of M\&A vis-à-vis sustainability. This is visible both in the sustainability and CSR strategy literatures, which consider firms only to grow organically, as well as in the broader management literatures where M\&As are studied, yet largely disregarding their sustainability considerations be it as regards motivation, processes, or long-term outcomes.

Research encapsulating actors at multiple levels of analysis is needed, across various types and sectoral contexts of sustainability transitions. To this end, Gonzalez-Porras et al. call for future research to study stakeholder engagement in sustainability at different levels of analysis, also including firms and industries, their coalitions, and the potential dynamics of competition therein. The information and legal transparency of supply chains is called for (Salminen \& Rajavuori). Rauter and Lämmerer see need for the study of firms across and within sectors to identify patterns, similarities and differences. Within organizations, there are calls to appreciate the complexity of corporate sustainability strategy making, given the many, at times contradictory, voices within organizations and in collaboration with stakeholders (Rauter \& Lämmerer; Salaiz et al.). In order to gain an enhanced understanding of sustainable consumption, it needs to be studied at different levels of analysis, comparing developing and developed countries, while also accounting for the context of post-modern social-media mediated societies (Rangwala \& Jayawardhena).

\section{Individual-level Agency}

Across the handbook chapters, there appears to be consensus that, as regards sustainability agency, there is a particular scarcity of research regarding individual-level agency. Such observations are made as regards the literature on sustainability transitions, whose focus actor-wise has tended to be on collectives, instead of individuals. Calls for further appreciation of individual-level psychological processes are made, be it as regards sustainability change agents, or consumers (Upham et al.; Sipilä), while acknowledging the potential difficulties in bridging ontological and epistemological paradigms between the theories underlying sustainability transitions on the one hand, and agency on the other. What is more, sustainability science arguably lacks a vocabulary to study individual actors (Jokinen et al.).

A similar state of affairs is visible as regards the study of businesses. While there has been overall scarcity of interest toward actors, this has been tilted toward strategic leaders and upper echelons, thus chief executive offices, top management teams, and boards of directors (Salaiz et al.), with less attention toward the role of middle managers and sustainability professionals (Birollo et al.) as well as employees (Russell et al.). Going forward, more attention toward top and middle managers' cognitive frames as well as the value-gap between individuals and their employing organizations is needed. Overall, there is need to better appreciate non-managerial agency toward sustainability in organizations, i.e. professionals and employees (Russell et al.) in non-managerial roles.

As regards individuals as consumers, there is need to appreciate how the broader context of one's life, for example as regards work- and home-related stress, affects sustainable consumption practices (Sipilä). While prior work in sustainable consumption has attended to life-end activities, more appreciation is warranted as regards the consumption decision (Rangwala \& 
Jayawardhena). Sustainability engagement in the digital era is called for in order to appreciate how consumers gather and engage with information from digital forms of media, including social media.

This handbook's overview of sustainability agency portrays the bulk of this research as occurring in disciplinary, phenomenon-based or actor-based silos. Going forward, integrative, multi-actor, and multi-level perspectives are needed to account for the diversity of actor types involved. In particular, the simultaneity of roles and their mutual spill-overs deserve attention. Zooming into the individual actor, i.e. you or me, individual actors operate simultaneously in numerous sustainability-related roles, be it as professionals at work, as customers in purchase decisions, or as residents and citizens, to name a few. Prior research reviewed in this handbook, however, does not account for the interconnections between these roles. Going forward, there are opportunities to study multi-role tasking, behavior spill-overs, as well as the paradoxes, tensions, and emotionality involved. The question is, are there within-individual role diversity and parallel protagonism vs. denial, and do these depend on the actor role or personality? What is the dance of sustainability antagonism vs. protagonism taking place within the self, within one's individual consciousness? How does such a chasm shift toward transformative sustainability behavior? In the context of any individual actor, the question is: What is it that we do, how is it that we act, on a daily basis, toward a sustainable future?

\section{Change Agency}

Many of the chapters in this handbook adopted the perspective of change agents to define sustainability agency. Going forward, more research on such 'transition agents' is needed (Jokinen et al.). In the example of institutional workers, more appreciation of their motivation and how they work with others is needed (Hermes \& Pawlak). Many of the chapters call for more research on the lived experience of sustainability workers, sustainability entrepreneurs, or change agents (e.g. Giæver \& Russell). Taking a closer look, more research on the actual practices of proactive structure-changing agency is needed (Giddens, 1984; Bandura, 2006). In this handbook, this has been observed in the context of institutional workers reformulating institutions (Hermes \& Pawlak) as well as how agency affects structure in the construction industry (Murtagh \& Sergeeva).

As regards forms of sustainability activism and change agency, there is need for knowledge integration and synthesis. While various activist types are identified (Mäkelä \& Olkkonen), future research could compare different activist types in action. What is more, the perspective might need turning upside down toward viewing incumbent actors, such as firms, as activists, appreciating how they act as agents of change at different levels and stages of sustainability transitions (Rauter \& Lämmerer). Similarly, the manifold perspective on sustainability change agents brought forward in this handbook deserves integration. Based on this handbook, sustainability change agents actively pursue a sustainability agenda, whether in incumbent or activist organizations. In other words, the perspective of sustainability agency emerging from this handbook tends to imply sustainability change agency, thus adopting a perspective to sustainability agency as proactive, intentional action toward a sustainable tomorrow.

Emotionality in sustainability work is raised in numerous chapters, including the paradoxes, ambivalence, and trade-offs involved. Going forward, emotions, be they positive or negative, deserve further study for example as regards established suitability change agents such as ecopreneurs, or emerging sustainability change agents such as employees. From an appreci- 
ation of coping strategies of change agents and consumers (Giæver \& Russell; Sipilä), future research could take inspiration from positive psychology (Cameron et al., 2003). Looked at from this perspective, the question of thriving at individual and collective levels becomes of interest. This leads us to ask: What if sustainability change agents, instead of merely coping, thrived? What if sustainability transitions were multi-level change processes characterized by individual and collective-level thriving dynamics?

Taking a critical perspective, extant research on actors within organizations, be they managers or employees, has been interested in sustainability change agents, i.e. those proactively driving a sustainability agenda. Going forward, the diversity of sustainability discourses and mindsets prevailing within organizations and throughout society, and the roles of actors within this multi-paradigmatic landscape needs to be appreciated. Which actor types deny or resist sustainability challenges such as climate change? How do they exercise their agency? How can such agency be geared toward sustainability? At the workplace, what are the behaviors, attitudes, and practices that are counterproductive toward a corporate sustainability agenda? What kinds of conflicts occur between protagonists and deniers, and how can such conflicts be avoided and/or turned toward transformative sustainability action? Integrative perspectives on the multi-faceted nature of sustainability actors, including the protagonists, deniers, and resisters is needed (Etchanchu et al.; Hermes \& Pawlak).

\section{Collaborative Agency}

Beyond individual- and firm-level agency, there is a need to appreciate collaborative forms of agency. To begin with, team or group dynamics matter in the context of top management teams, departmental work communities, or communities of change agents within organizations. As an example, the question of cognitive diversity in top management teams, and its effect on an organization's strategic direction, deserves further study (Salaiz et al.).

Moreover, the question of collective action within and across incumbent and activist public/ private organizations deserves attention. Better appreciations of collective forms of agency, be it between individuals or between organizations, are thus needed. To this end, many questions remain open to further study. For example, what is the effect of actor diversity on distributed agency (Engez et al.)? How does individual-level action aggregate to collective levels? What is sustainability engagement in the digital age? For example, what is the role of social media in enabling societal transformations (Etchanchu et al.)?

Sustainable futures are developed in collaboration with others. Questions of collaboration thus deserve further attention. While many fields of study refer to the importance of collaboration, across sectors and interest groups, it is rare that collaboration is studied. The question of 'how' to enable cooperation, in various contexts of sustainability transitions, deserves further attention. What, indeed, is cooperation? How to effectively manage cross-sector multi-stakeholder partnerships toward trusting and sustainability transformative directions (Gray \& Dewulf)? What is agency in the context of ecosystems, at the crossroads between individual, organizational and ecosystem agency (Aarikka-Stenroos et al.)? How do ecosystems evolve?

Furthermore, the role of non-human agency deserves recognition as part of the discussion on sustainability agency, given that the debate on agency seems to be biased toward the study of human forms of agency. As the chapter by Jokinen et al. observes, there are numerous ways to account for material agency in the context of sustainability transitions. Going forward, 
research on material agency in sustainability transitions is called for, as well as its interconnections with human agency, thus forms of inter-agency (Jokinen et al.).

Taking a critical stance, it appears that as long as nature is not recognized by mainstream social scientists as a form of material agency, its role in shaping and influencing sustainability transitions is left unattended to. Nature is a living resource, and a singularly important one, given that the livelihoods of human and animal species depend on the health of nature. All the while, current forms of theorizing tend to omit nature, dealing with it at best as a 'resource' or 'transaction cost'. If sustainable futures are to become reality, then the role of nature, and its agency, needs close attention.

\section{CLOSING WORDS}

Unless imminent and continuous sustainability action is undertaken, the future of humanity is uncertain. Our generation is not just living through a 'major trend' of spiraling worldwide unsustainability. Instead, the very survival of humankind and nature's ecosystems, in their present form, is at stake. Put bluntly, we do not know whether, going forward, the planet's natural ecosystems are able to cope with the contemporary lifestyle of human beings. What we have accustomed to labeling as 'normal', such as material wealth, economic growth, endless consumption, is destroying the livability of the ecosystems upon which our survival depends. We, humankind, have created this problem. Accordingly, it is our responsibility to solve it.

While there is a wealth of scientific research in the realm of the natural sciences on the natural environment, the social scientists have more gradually shifted their attention to the study of the social issues involved in systemic change toward sustainable futures. Within this remit, the question of 'whose role' are societal sustainability transformations has been raised. At the individual level, faced with increasingly negative news in recent years, a number of us have asked the question: Do my daily actions matter vis-à-vis a sustainable tomorrow? Can I make a difference? If so, how? And does it really matter? Such questions have increasingly been raised by our university students. As scholars, we wanted not only to start making a difference in our own lives, but we also felt that our duty and responsibility as scholars and educators is to have (at least some) means and lever to answer and deal with the question that appears to be the burning question of our times: How can I make a difference toward sustainable futures?

We decided to embark on reviewing the existing knowledge on the subject matter. In reviewing this body of work, we soon came to recognize that there was not one search term, not one theory, not one discipline we could turn to in order to answer the question of 'what is known on active sustainability actors based on current scientific research?' As academics representing different disciplines, we were puzzled and felt somewhat disheartened. We had no answer. Yet, we recognized that the term 'agency' is used, particularly in sustainability science, albeit with different connotations. Moreover, 'agency' is a classic term, used across the social sciences, that delves into the capacity to act, and oftentimes is bet against the prevailing societal structures. As such, agency seemed to provide an umbrella concept capable of reaching out to the classics across social sciences, while also being relevant in the empirical and contemporary context of sustainability transformations.

We embarked on this interdisciplinary handbook project with the humble aim of making sense of what is known on the role of actors actively pursuing sustainability agendas. In other 
words, what is the state of the art, across the social sciences, as regards sustainability agency. We recognized that the best way of making sense of 'what is known on sustainability agency' is by asking the experts, per area, to review the field of work within their expertise, as regards notions related and relevant to sustainability agency.

As this handbook project nears its closing, it is time for a synthesis. This handbook consists of 25 chapters, each reviewing the state of the art as regards one particular type of sustainability agency, some also providing empirical evidence in support of their argument. Each offers a contribution as regards a particular type of sustainability agency.

In preparing this chapter, we had the opportunity of engaging in a meta-review of the handbook's chapters, be it as regards methods, theories, concepts, or findings. It is via such a multi-review approach that the findings of this handbook, at an integrative level, bear implications for further research on sustainability agency. We observed sustainability agency to offer a broad enough umbrella concept to encapsulate the many practiced forms of sustainability-related actorhood. Based on the handbook's chapters, we define sustainability agency as: 'intentional, proactive individual or collective-level action geared toward sustainable futures, also involving interaction with non-material forms of agency'.

The study of sustainability agency spans the social sciences, its disciplines, and sub-disciplines, and relies on its meta-theories while blending them with mid-range theories and localized, phenomenon-based literatures and bodies of knowledge. In this handbook, the focus was on environmental sustainability, which was approached in the chapters via sustainability transitions, wicked phenomena such as climate change or the circular economy, and the sustainability strategies of cities, and the private sector businesses.

Numerous forms of sustainability agency were identified by the handbook's chapters (see Table 27.5), from individual-level action in professional, within-organizational roles to consumer and citizen roles. Further, forms of active agency via entrepreneurial or institutional work, grassroots or social movements, and forms of activism were also identified, as were forms of institutionalized agency via legislation, formal and informal economies, government and city action, as well as business strategy. In addition to being the remit of individuals or collectives, sustainability agency bears a distinctly relational element in that it often occurs in collaboration with other individuals, organizations, and/or material resources. It is thus that stakeholder engagement, projects, partnerships, mergers, networks, and ecosystems are all simultaneously forms of sustainability agency, while also offering platforms for sustainability agency to emerge in collaboration with others. Sustainability agency, regardless of its form, was often observed to involve paradoxes, trade-offs and tensions. In summary, there is a plethora of terminology that fits under the broad metaphor of sustainability agency, as disciplines and literatures offer different, either converging or competing, conceptualizations and operationalizations of sustainability agency. It is a delight to notice that the study of sustainability agency, regardless of its form and discipline, is gaining momentum, year by year.

Nevertheless, a number of questions remain to be answered. Notwithstanding, the handbook offers a rich agenda for future research. Calls for future research span from prevailing paradigms and meta-narratives to the individual, passing by the institutional, organizational and collaborative realms. Narratives of hope and action are needed to enable agency, instead of narratives of fear that paralyze action. A critical discussion on the ability of prevailing economic paradigms to support the required systemic transformations is called for. Unless action is taken, private law appears to enable the perpetuation of unsustainable forms of business. Particularly, there is a dearth of research on sustainability agency in informal economies and 


\section{Table 27.5 Actor types according to the structure of the handbook}

\begin{tabular}{|c|c|c|}
\hline Chapter no. & Authors & Actor type \\
\hline \multicolumn{3}{|c|}{ Part I: Individual agency } \\
\hline 2 & Upham et al. & Individual actors \\
\hline 3 & Salaiz et al. & $\begin{array}{l}\text { Upper echelons, strategic leaders, i.e. top managers, CEOs, } \\
\text { board directors }\end{array}$ \\
\hline 4 & Birollo et al. & $\begin{array}{l}\text { Middle managers, project managers in charge of implementing } \\
\text { CSR/SD initiatives, or CSR managers, CSR professionals, } \\
\text { ethics officers }\end{array}$ \\
\hline 5 & Mountfield et al. & Middle managers \\
\hline 6 & Russell et al. & $\begin{array}{l}\text { Define term employee sustainability behaviors, which } \\
\text { includes employee green behaviors, workplace/employee } \\
\text { pro-environmental behaviors, employee sustainability change } \\
\text { agency, employee CSR behaviors }\end{array}$ \\
\hline 7 & Sipilä & $\begin{array}{l}\text { Individual consumers, as micro-level agents in sustainability } \\
\text { transitions who can drive sustaibaility via their consumption } \\
\text { behavior (Caruana \& Chatzidakis 2014) }\end{array}$ \\
\hline \multicolumn{3}{|c|}{ Part II: Active agency } \\
\hline 8 & Hermes \& Pawlak & Institutional workers \\
\hline 9 & Mäkelä \& Olkkonen & $\begin{array}{l}\text { Sustainability activism/t (different types identified): agent } \\
\text { of activism can be individual (e.g. private person, CEO), } \\
\text { organization (firm, NGO), a group of individuals (consumers), } \\
\text { or embedded agency where one seeks to change one's own } \\
\text { organization (Battilana 2006) }\end{array}$ \\
\hline 10 & Giæver \& Russell & Ecopreneurship as sustainability agency \\
\hline 11 & Lehtimäki et al. & Social entrepreneurship \\
\hline 12 & Hoppe \& Warbroek & $\begin{array}{l}\text { Citizen, citizen collectives, community energy (or community } \\
\text { of place/interest/community power/community energy } \\
\text { initiative, renewable energy cooperatives) }\end{array}$ \\
\hline 13 & Etchanchu et al. & $\begin{array}{l}\text { Social movement, i.e. civil society actors (spans a variety } \\
\text { of initiatives of collective action to advance environmental } \\
\text { concerns, often around climate change) }\end{array}$ \\
\hline \multicolumn{3}{|c|}{ Part III: Relational agency } \\
\hline 14 & Gonzalez-Porras et al. & $\begin{array}{l}\text { Stakeholder engagement as change agency, stakeholders as } \\
\text { change agents }\end{array}$ \\
\hline 15 & Gray \& Dewulf & Partnerships as agents of change \\
\hline 16 & Reynolds \& Hassett & Mergers and acquisitions \\
\hline 17 & Aarikka-Stenroos et al. & $\begin{array}{l}\text { Ecosystem actors, agency in ecosystems, ecosystems and } \\
\text { agency (system outcomes, heterogeneous community of actors, } \\
\text { varying roles, interdependent), agency is different depending } \\
\text { on the ecosystem type }\end{array}$ \\
\hline 18 & Murtagh \& Sergeeva & Agency in construction \\
\hline 19 & Engez et al. & Distributed agency \\
\hline 20 & Jokinen et al. & Inter-agency \\
\hline \multicolumn{3}{|c|}{ Part IV: Governance } \\
\hline 21 & Salminen \& Rajavuori & $\begin{array}{l}\text { Sustainability agency is not used in law, yet the terms } \\
\text { sustainability and law are used. Role of law on sustainability }\end{array}$ \\
\hline
\end{tabular}




\begin{tabular}{|c|c|c|}
\hline Chapter no. & Authors & Actor type \\
\hline & & $\begin{array}{l}\text { agency; (1) state-driven regulatory projects that impose } \\
\text { public law statutory requirements; calibrates agency toward } \\
\text { sustainability after action via regulatory instruments; (2) private } \\
\text { governance initiatives create (un)sustainability agency }\end{array}$ \\
\hline 22 & Krystallis \& Koistinen & Governments as agents of sustainability \\
\hline 23 & Hoppe & Agency of local government, i.e. cities \\
\hline 24 & Rauter \& Lämmerer & Companies \\
\hline 25 & Rangwala \& Jayawardhena & Consumers \\
\hline 26 & Gröschl & $\begin{array}{l}\text { Sustainability agency in informal economy settings, informal } \\
\text { workers such as informal waste pickers, food markets sellers }\end{array}$ \\
\hline
\end{tabular}

in developing countries. Yet, combined, these contexts account for a large part of the world's population. This conundrum needs attention.

Interest is shifting from the study of institutional actors to the study of organizational and individual actors. Prior research appears to have focused on motivations (i.e. the question of 'why') instead of the execution and practices (i.e. the question of 'how') of organizations and individuals engaged in sustainability action. In particular, the paucity of research on individual-level agency is lamented, across disciplines. From an interest in top managers, emphasis on middle managers and employees as active sustainability agents is called for. Strikingly, individuals have been studied in role-based silos, as consumers, citizens, residents, or professionals, with less attention to the cross-overs between these roles. Yet, role-based cross-over is our daily lived experience. The bulk of the research on sustainability agency implies or adopts an assumption of sustainability actors as change agents, experiencing a multiplicity of emotions as they undertake this work. Taking a critical stance, though, there is need to appreciate the deniers and antagonists of sustainability as well, within organizations and/or in society at large.

As regards forms of relational agency, there is need to understand how cognitively diverse teams, such as management teams, make decisions. Further, how does collective action emerge and aggregate from one level of analysis to the other? How does sustainability engagement occur in the post-modern digital era? While sustainability agency often occurs in multi-stakeholder partnerships and ecosystems, these forms of collaboration need to be better understood. The question of how sustainability relates to the actual practice of merging and acquiring deserves critical scrutiny. As sustainable futures are developed in multi-party collaboration, the notion, practice and dynamics of collaboration between individuals, organizations, and material needs attention given the trade-offs needed as parties engage in collaboration with oftentimes differing assumptions, mental mindsets, and objectives.

Across all forms of sustainability agency, opportunities for cross-fertilization and knowledge integration and synthesis abound. In particular, integrative, multi-actor, multi-level perspectives on sustainability agency shaping prevailing societal structures and engaging in systemic change is needed.

In closing, this handbook is a call for sustainability action. A call for individual-level agency as professional, consumers, citizens. A call for academic agency. A call for organizational and institutional agency. A call for collaborative agency. In sum, a call for sustainability agency. 


\section{ACKNOWLEDGEMENTS}

The authors are appreciative to the From Innovation to Business Ecosystems (CICAT2025) project (0245896-2018) of the Strategic Research Council of the Academy of Finland, which has supported the work reported here.

\section{REFERENCES}

Antonetti, P., \& Maklan, S. (2014), 'Feelings that make a difference: How guilt and pride convince consumers of the effectiveness of sustainable consumption choices', Journal of Business Ethics, 124(1), $117-134$.

Bandura, A. (2006), 'Toward a psychology of human agency', Perspectives on Psychological Science, 1(2), 164-180.

Barker, C. (2003), Cultural studies: Theory and practice. London, Thousand Oaks, CA, New Delhi: Sage Publications.

Battilana, J. (2006), 'Agency and institutions: The enabling role of individuals' social position', Organization, 13(5), 653-676.

Battilana, J., Leca, B., \& Boxenbaum, E. (2009), 'How actors change institutions: Towards a theory of institutional entrepreneurship', Academy of Management Annals, 3(1), 65-107.

Caldwell, R. (2003), 'Models of change agency: A fourfold classification', British Journal of Management, 14(2), 131-142.

Cameron, K., Dutton, J. E., \& Quinn, R. E. (2003), Positive organizational scholarship. San Fransisco: Berrett-Koehler.

Caruana, R., \& Chatzidakis, A. (2014), 'Consumer Social Responsibility (CnSR): Toward a multi-level, multi-agent conceptualization of the "Other CSR", Journal of Business Ethics, 121(4), 577-592.

Clark, W. C., \& Dickson, N. M., (2003), 'Sustainability science: The emerging research program', Proceedings of the National Academy of Sciences of the United States of America, 100(14), 8086-8091. doi: 10.1073/pnas.1231333100.

Dean, T. J., \& McMullen, J. S. (2007), 'Toward a theory of sustainable entrepreneurship: Reducing environmental degradation through entrepreneurial action', Journal of Business Venturing, 22(1), 50-76. doi: https://doi.org/10.1016/j.jbusvent.2005.09.003.

DiMaggio, P. (1988), 'Interest and agency in institutional theory', in L. G. Zucker (ed.), Institutional Patterns and Organizations: Culture and Environment (pp. 3-22). Cambridge, MA, USA: Ballinger.

Enfield, N. J., \& Kockelman, P. (2017), Distributed agency. Oxford, New York: Oxford University Press USA - OSO.

Geels, F. W. (2002), 'Technological transitions as evolutionary reconfiguration processes', Research Policy, 31(8-9), 1257-1274.

Giddens, A. (ed.) (1984), The constitution of society: Outline of the theory of structuration. Berkeley, CA: University of California Press.

Harty, C. (2008), 'Sociology and construction management research: Issues, approaches and implications', Paper presented at the 24th Annual ARCOM Conference, Cardiff, UK.

Kates, R. W. et al. (2001), 'Environment and development. Sustainability science', Science, 292(5517), 641-642. doi: 10.1126/SCIENCE.1059386.

Koistinen, K. (2019), Actors in sustainability transitions, Acta Universitatis Lappeenrantaensis 846. Lappeenranta: LUT University.

Latour, B. (2005), Reassembling the social: An introduction to actor-network-theory. Oxford: Oxford University Press.

Pelenc, J., Bazile D., \& C. Ceruti (2015), 'Collective capability and collective agency for sustainability: A case study', Ecological Economics, 118, 226-239.

Smith, A., Stirling, A., \& Berkhout, F. (2005), 'The governance of sustainable socio-technical transitions', Research Policy, 34 (10), 1491-1510. 
Satu Teerikangas, Katariina Koistinen, Tiina Onkila, and Marileena Mäkelä - 9781789906035 Downloaded from PubFactory at 04/26/2023 02:39:57AM 